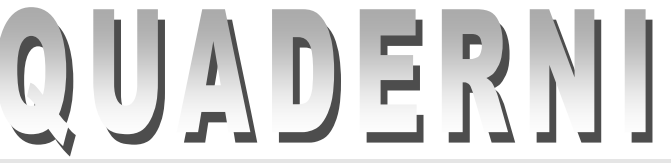

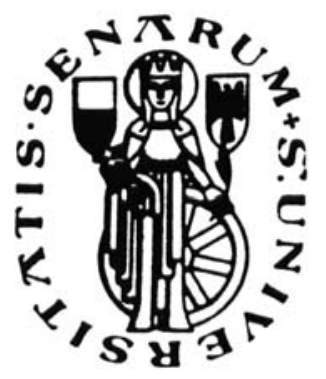

Università degli Studi di Siena

\section{DIPARTIMENTO DI ECONOMIA POLITICA}

SYDNEY AFRIAT

CARLO MILANA

The Super Price Index: Irving Fisher, and after

n. 492 - Gennaio 2007 


\begin{abstract}
It is submitted that, for the very large number of different traditional type formulae to determine price indices associated with a pair of periods, which are joined with the longstanding question of which one to choose, they should all be abandoned.

A method is proposed whereby price levels associated periods are first all computed together, subject to a consistency of the data, and then price indices that are all true are determined from their ratios. An approximation method can apply in the case of inconsistency.
\end{abstract}

Key words: price level, price index, non-parametric, index-numbers, index-number problem, index-number theorem, revealed preference.

Jel Classification: C43, E31.

Contributing to Specific Targeted Research Project "EUKLEMS-2003—Productivity in the European Union: A Comparative Industry Approach" supported by the European Commission with Contract No. 502049 (SCS8) within the Sixth Framework Programme.

Sydney Afriat, Department of Economics, University of Siena

Carlo Milana, Istituto di Studi e Analisi Economica, Rome 


\title{
The Super Price Index: Irving Fisher, and after
}

\author{
S. N. Afriat ${ }^{1}$ \\ and
}

Carlo Milana ${ }^{2}$

\section{Introduction - or genesis}

Prices change and an individual who enjoys a consumption that provides a certain standard of living at a certain money cost would like to know how much it will cost to maintain the same standard at the new prices. idea.

Reference may be made to this first paragraph for the basis of the price-index

There is of course no absolute theoretical reason for having a price index in the first place. It is an institution, even if a well established, traditional, and perhaps even today still needed institution, affecting many aspects of economic life.

The Price Index issued from the Statistical Office is a number that tells everyone how to answer the mentioned question, the index being the multiplier of old expenditure to determine the new. They must change expenditure in proportion to the index to keep the old standard of living. All have submissively to accept the authority of the number produced no doubt on some basis quite likely beyond them.

The question of how to produce such an extraordinary number is called The Index-Number Problem. It stands out as a fascinating question that has appealed to and occupied a great number of economists. To proceed, there are primitive points to be added. Let $P_{s t}$ denote the price index from period $s$ to period $t$.

For a first point, the number must apply equally well to everyone experiencing the price change, whatever their standard of living. Hence an expenditure $M_{s}$ in period $s$, at whatever level, must be replaced by

\footnotetext{
${ }^{1}$ Economics Department, University of Siena, afriat@unisi.it.

2 Istituto di Studi e Analisi Economica, Rome, c.milana@isae.it, contributing to Specific Targeted Research Project "EUKLEMS-2003-Productivity in the European Union: A Comparative Industry Approach" supported by the European Commission with Contract No. 502049 (SCS8) within the Sixth Framework Programme.
} 


$$
M_{r}=P_{r s} M_{s}
$$

in period $r$ to maintain the same standard of living. This point seems not to be explicitly represented among Irving Fisher's famous price-index formula "Tests"3, but the next points are-though we are not now considering formulae but the basic idea of a price-index.

For the Identity Test, there is the statement

$$
P_{t t}=1 \text {, }
$$

that is, "when one year is compared with itself, the index shows 'no change'." Most formulae go along with this.

For the next, if the price change is reversed, so the new prices becoming the old and vice-versa, then the price index, the ratio that turns old expenditure into new, is replaced by the reciprocal. That is,

$$
P_{t s}=\left(P_{s t}\right)^{-1}
$$

which is the Time Reversal Test. Fisher's "ideal” index is just about the only formula that satisfies this. No wonder it is "ideal".

This thinking seems to be as if the price index was derived as a ratio of pricelevels, expressing purchasing power of money for obtaining a standard of living by purchase of consumption.

That has in fact already been offered as a way to go with The Index Number Problem, by Afriat (1981), with what may now be called The New Formula, though it is not at all a formula of the type dealt with by Fisher and associates. First determine price levels, and then determine price indices as their ratios. That is, instead of the price index being given directly by some formula, among those produced seemingly endlessly and as it were out of nothing (Irving Fisher, joined by others, deals with one or two hundred of them).

True, there are many prices each with its own separate level, so it may seem fair to ask what sense can there be to their having a single level when they are taken together. None the less there is a somewhat restricted but nevertheless outstanding sense for it.

But first there will be account of the early maker of index numbers, Irving Fisher, who knew well about the primitive price index idea but not this sense.

For a distinction and the language for it: price level has reference to a single period, while price index has reference to two, and is in principle the ratio of new level to old, so it is the multiplier of old expenditure to produce the new that will currently purchase the same living standard.

The second primitive principle mentioned, expressed by Fisher's Time Reversal Test, would also be an immediate consequence of taking price indices having the form of ratios of price levels.

When dealing with more than just two periods, beside the Time Reversal (the Fisher Index is a distinguished case among formulae for satisfying this) there can be introduction of the Chain Test,

$$
P_{r s} P_{s t}=P_{r t}
$$

(just about never satisfied by any of the one or two hundred usual price index formulae) which implies Time Reversal again, and moreover implies, and obviously

\footnotetext{
${ }^{3}$ See Fisher (1922), Allen (1975), Section 1.8, or Afriat and Jazairi (1988).
} 
is implied by, price indices being expressible as the ratios of a set of numbers associated with the periods - the 'price levels'. For, bringing in the Identity Test,

$$
P_{t t}=1
$$

we have

$$
P_{t s} P_{s t}=P_{t t}=1
$$

so

$$
P_{t s}=\left(P_{s t}\right)^{-1}
$$

which is Time Reversal, and now, for any fixed $r$,

$$
P_{s t}=P_{s r} P_{r t}=P_{s r}\left(P_{t r}\right)^{-1}=P_{s r} / P_{t r}
$$

so price indices determined relative to a fixed base can serve as 'price levels' from which all price indices can be determined as their ratios. Evidently now the Chain Test, from first implying Reversal, is equivalent to Fisher's Circularity Test,

$$
P_{r s} P_{s t} P_{t r}=1 \text {. }
$$

While there has been invariably no prior determination of price levels from which to obtain price indices as their ratios, the (1981) New Formula excepted, usually formulae (a great number) are proposed that go directly to the index without a background of levels. In that culture the great headache is to know what formula-as may be good, or true, or ... or what?

A missing test, not named before and which implies all these others, and which can be called the Ratio Test, is simply that the price index be expressed as a ratio of a set of numbers, maybe price levels. Among formulae, as such, nowhere is that satisfied, unless the 1981 New Formula be allowed, or another, mysteriouly neglected,

$$
P_{s t}=p_{t} a / p_{s} a
$$

the inflation rate for a fixed bundle of goods $a$. "It could be wondered why this formula was not "ideal" for Fisher. Possibly it was too dull but if he was looking for a more interesting one which meets the proper qualification, ..." 4

This is a moment also to quote Sir Roy Allen (1978, p. 418) where he quotes one of us:

"Formerly, it was as if an answer was proposed without first having had a question, and it was wondered if it could be an answer to a question, any question at all. Even many answers to no question in particular were proposed-the names of their proposers are attached to some of them" (Afriat 1977, p.102)

That has to do with the formula approach dominated by Fisher and, as if caught in a trap, still prevalent. For the truck with index formulae does not end with Fisher.

\footnotetext{
${ }^{4}$ The quotation is from Afriat (1977) 37-8, and continues “... it does not exist, as Eichhorn (1976) has shown.” Unfortunately friend Wolfgang Eichhorn, and for that matter Afriat, had not known the 1981 New Formula.
} 


\section{Fisher, and after}

Irving Fisher (1922, 244-48) ranked 134 index number formulas (according to one of us, 126, and 145 by the count of Yrjo Vartia) according to their numerical distance from the "ideal" geometric mean of the Laspeyres and Paasche indices and separated them into several classes, as it were in increasing order of merit.

The first twelve index numbers, constituting the first of these classes, are labeled as "worthless", to designate that they are the worst in his ranking. The other six classes are labeled as poor, fair, good, very good, excellent, and superlative (p. 244).

Fisher (1922, 244-48) classified ten (or eleven to include the yardstick Fisher "ideal”) index number formulas in the "superlative" group because, in his numerical example, they performed very closely to formula 353, which is the "ideal" geometric mean of the Laspeyres and Paasche indexes, which was itself put at the top rank in this group.

He claimed that all these formulas correspond to combinations of the Laspeyres and Paasche, including the direct and implicit Walsh index numbers, one combination of these last two formulas, and a couple of combinations of direct and implicit Törnqvist-type index numbers. Reference can always be made to our Appendix for Fisher's list, and an exhibition of his "superlative” and other formulas.

In the numerical example worked by Fisher, the closest formula to 353 is 8053, which is the arithmetic average of 53 and 54 where 53 is Laspeyres index number (p. 471) and 54 is Paasche index number (p. 471). Fisher claimed that all the other "superlative" index numbers are combinations of 53 and 54. As remarked again later, we do not here regard Laspeyres and Paasche as formulae like the others that are offered as price-index formulae, but in a category of their own.

Of late there has been new venture towards the super, and beyond ... Evidently, except the implicit Walsh index number and Fisher's “ideal” itself, Diewert's (1976) “superlative” index numbers are not superlative in Fisher's (1922, 244-48) sense. The implicit Walsh index number, which is given by formula 1154 in Fisher's list, corresponds to Diewert's quadratic mean of order-1 index number, whereas Fisher's “ideal” index number corresponds to Diewert's quadratic mean of order-2 index number. As set forth by Milana (2005); Diewert's and Fisher's indexes cannot understandably be defined as, in some way, approximating the actual but unknown true index number up to the second order, or something like that, in order to admit them as "superlative" in the language of Diewert $(1976,1978)$. With all that, such a formula seems to be essentially no novelty but a continued adherence to the old formula world, only bringing to it an added unconstructive impenetrable burden of complexity.

After the casting around for the super coming from Irving Fisher, there is entry into an entirely new kind of territory beckoning exploration. A question is whether here is a breakthrough to a new, highest quality formula, as the language would suggest, here and there acclaimed as such, or a neo-Fisherian casting around without new guidance.

In order not to get lost in this enquiry, a start should be made at the beginning. One of us had a dedicated immersion in the entire super literature, while the other, saved by reductio ad absurdum, had never before our encounter ever put eyes on a single item of the later phase. 


\section{Data and formulae}

Reference is made to two spaces, the budget and commodity spaces $B$ and $C$, one the space of non-negative row vectors, and the other of column vectors. With $\Omega$ the nonnegative numbers, $B=\Omega_{n}, C=\Omega^{n}$, so with $p \in B, x \in C$ we have $M=p x \in \Omega$ as the money cost of the bundle of goods $x$ at the prices $p$. With such a purchase, making the demand observation $(p, x) \in B \times C$ of commodities $x$ at the prices $p$, the budget vector is $u=M^{-1} p \in B$, for which $u x=1$. With such a purchase, there is the revealed preference of $x$ over every bundle $y$ which, being such that $u y \leq 1$, is also attainable at no greater cost.

A fundamental area of discussion involves data consisting of a pair of demand observations $\left(p_{t}, x_{t}\right) \in B \times C(t=0,1)$, which is associated with the Laspeyres index

$$
\hat{P}_{s t}=p_{s} x_{t} / p_{t} x_{t}
$$

and Paasche index

$$
\breve{P}_{s t}=p_{s} x_{s} / p_{t} x_{s}=\widehat{P}_{t s}^{-1} \text {. }
$$

There is also the Fisher index

$$
\bar{P}_{s t}=\left(\widehat{P}_{s t} \breve{P}_{s t}\right)^{\frac{1}{2}}
$$

which is the geometric mean of both, lying between them. A condition on the demand data having a central significance is the Laspeyres-Paasche inequality

$$
\text { (LP) } \breve{P}_{s t} \leq \hat{P}_{s t},
$$

equivalently

$$
\hat{P}_{s t} \hat{P}_{t s} \geq 1
$$

or again

Or with

$$
p_{s} x_{s} p_{t} x_{t} \leq p_{s} x_{t} p_{t} x_{s}
$$

$$
L_{s t}=p_{s} x_{t} / p_{t} x_{t}
$$

again the Laspeyres index, this condition is equivalent to the solubility of the system of inequalities

$$
\text { (L) } \quad L_{s t} \geq P_{s} / P_{t}
$$

for price levels $P_{t}(t=0,1)$. Put this way, the usual Laspeyres-Paasche inequality condition for a pair of demands with $t=0,1$ is immediately generalized for any number $t=0,1,2, \ldots, m$ as in the (1981) New Formula. ${ }^{5}$

The system $L$ with $s, t=0,1$ requires

$$
\breve{P}_{01} \leq P_{1} / P_{0} \leq \widehat{P}_{01}
$$

so its consistency, defining $L$-consistency, or the existence of a solution, is equivalent to the $L P$-inequality.

\footnotetext{
${ }^{5}$ It is interesting that a simple step like this should open the door to a fundamentally new approach. The start was at least a quarter-century ago, but the significance of it was recognized more recently.
} 
Here it is convenient to insert, though we have no immediate concern there, that the counterpart for more than two demands is the cyclical Laspeyres product test

$$
L_{t i} L_{i j} \cdots L_{k t} \geq 1 \text { for every cycle } t, i, j, \ldots, k, t,
$$

which is a strengthening of the revealed preference test for utility construction that serves for conical utility. Introducing the chain Laspeyres and Paasche indices

$$
\widehat{P}_{s i j \ldots k t}=\widehat{P}_{s i} \widehat{P}_{i j} \cdots \widehat{P}_{k t}, \quad \breve{P}_{s i j \ldots k t}=\breve{P}_{s i} \breve{P}_{i j} \cdots \breve{P}_{k t},
$$

this is equivalently to

$$
\text { (chain } L P \text { ) } \quad \breve{P}_{s \ldots t} \leq \widehat{P}_{s \ldots t}
$$

for all possible chains ... taken separately. Hence introducing the new Laspeyres and Paasche indices

$$
\widehat{\Pi}_{s t}=\min _{i j \ldots k} \widehat{P}_{s i} \widehat{P}_{i j} \cdots \widehat{P}_{k t}, \quad \breve{\Pi}_{s t}=\max _{i j \ldots k} \breve{P}_{s i} \breve{P}_{i j} \cdots \breve{P}_{k t},
$$

this is equivalent to

$$
\text { (new } L P \text { ) } \quad \breve{\Pi}_{s t} \leq \widehat{\Pi}_{s t} .
$$

This extended approach is dealt with more fully in the papers of 1981 and 1982. But we should not now get sidetracked and should return now to the basic case of two demand observations, having touched briefly on this beginning of the extension.

Going back to the monumental first paragraph, one obvious way of maintaining, at new prices, the old standard of living obtained from the old consumption $x_{0}$ at a money cost $p_{0} x_{0}$ is to simply buy the old consumption with new cost $p_{1} x_{0}$. So certainly the current cost of the old standard is a most that amount, and its comparison with the old cost, which might at first thought serve as a price index, is at most $p_{1} x_{0} / p_{0} x_{0}$, which is the ever-pervasive Laspeyres index.

But here common sense breaks in with the proposal that one would not necessarily buy the old bundle at the new prices, one could buy instead another bundle that provides at least the old standard perhaps at a lesser minimum cost, making a comparison ratio with the old cost, the price index $P_{10}$, not exceeding the Laspeyres index,

$$
P_{10} \leq p_{1} x_{0} / p_{0} x_{0}
$$

and by the same principle

$$
P_{01} \leq p_{0} x_{1} / p_{1} x_{1}
$$

But in recollection of the second primitive point which asserts

$$
P_{01}=\left(P_{10}\right)^{-1}
$$

this second is equivalent to

$$
P_{10} \geq p_{1} x_{1} / p_{0} x_{1}
$$

so common sense together with the primitive reversal principle provides both Laspeyres and Paasche, and shows them not only as tied together with the same source in principles, but as upper and lower bounds of the price index. In a way, they 
are not price-index formulae like all the others, but fundamental and irrefutable limits for the price index.

In that case, of course, the lower bound could not exceed the upper bound. J. R. Hicks (without proving anything) calls that "The Index Number Theorem" (Revision, 1956, p. 181.) One should remember there was a time when there was, briefly, something of a fashion to call almost anything a "Theorem". It is confusing, but perhaps Hicks was just being fashionable. Anyway, a case where Paasche turned out to be greater than Laspeyres could be occasion for a pause.

It might have been good sense (corresponding to practice of the practical) to abandon the entire theoretical subject after arrival at this point, where the unavoidable primitive has been joined with common sense. But uncountable formulae for the index, good, true, better, super, \&c have been proposed.

To go further, as it seems we must, more form needs to be given to ideas we have so far.

\section{Utility}

There are two main things about a consumption bundle $x \in C$. The simple part is that it has a money cost $M=p x \in \Omega$ when the prices are $p \in B$. The other part is that it is the basis - and having it is the objective, use, use-value, or utility-for obtaining a standard of living, with the sacrifice of cost. Hence there is a link between cost and standard of living, where prices enter. For this link a gap remains between consumption and its utility, made good hypothetically by introduction of the utility function.

A utility function is any numerical-valued function $\phi$ defined on the commodity space $B$,

$$
\phi: B \rightarrow \Omega
$$

so $\phi(x) \in \Omega(x \in B)$ is the utility level of any commodity bundle $x$.

A utility function $\phi$ determines a utility order $R \subset C \times C$ where

$$
x R y \equiv \phi(x) \geq \phi(y)
$$

A utility function $\phi$, with order $R$, fits a demand element $(p, x)$, with budget vector $u$, or the demand is governed by the utility, if the revealed preferences of it belong to the utility order,

$$
u y \leq 1 \Rightarrow x R y(y \in C) .
$$

In other words, if $x$ has at least the utility level of every bundle $y$ attainable at no greater expenditure with the prices, or $x$ provides the maximum utility $\phi(x)$ for all those bundles $y$ under the budget constraint $u y \leq 1$, that is

$$
p y \leq p x \Rightarrow \phi(x) \geq \phi(y) .
$$

The utility system is hypothetical and admitted to the extent that it fits available demand observations. The cost of a standard of living is determined as the minimum cost at prevailing prices of getting a consumption that provides it. In terms of a utility function $\phi$, this is gathered from the utility-cost function 


$$
c(p, x)=\min \{p y: \phi(y) \geq \phi(x)\}
$$

which tells the minimum cost at given prices $p$ of obtaining a consumption $y$ that has at least the utility of a given consumption $x$. Since $x$ itself, with cost $p x$, is a possible such $y$, necessarily

$$
c(p, x) \leq p x \text { for all } p, x
$$

while

$$
c(p, x)=p x
$$

signifies the admissibility, under government by the utility system, of the demand of $x$ at the prices $p$. It shows the demand is cost effective, getting the maximum of utility available for the cost, and cost-efficient, getting at minimum cost the utility obtained, which conditions would here be equivalent. A case where admissibility does not hold could be attributed to consumption error, described as failure of efficiency, where

$$
c(p, x) \geq e p x, \quad 0 \leq e \leq 1
$$

would show attainment of cost efficiency to a level $e$. This idea has some use in dealing with demand data inconsistent with government by a utility by fitting it to a utility that serves only approximately, as in Afriat (1973).

For the service of a price index this utility-cost should factorize into a product

$$
c(p, x)=\theta(p) \phi(x),
$$

of price-level $P=\theta(p)$ depending on $p$ alone and quantity level $X=\phi(x)$ depending on $x$ alone. This immediately is assured if $\phi$ is conical, but also the converse is true, showing the following ${ }^{6}$

THEOREM For factorization of the utility-cost function it is necessary and sufficient that the utility be conical.

This Theorem may be a good candidate for the title "The Index Number Theorem" secured by Hicks for another purpose as already noted, and we are going to prove it (if it was not already, probably long ago ${ }^{7}$ ).

Given $\phi$ conical,

$$
\begin{aligned}
c(p, x) & =\min \{p y: \phi(y) \geq \phi(x)\} \\
& =\min \left\{p y(\phi(x))^{-1}: \phi\left(y(\phi(x))^{-1}\right) \geq 1\right\} \phi(x) \\
& =\theta(p) \phi(x)
\end{aligned}
$$

where

$$
\theta(p)=\min \{p z: \phi(z) \geq 1\}
$$

\footnotetext{
${ }^{6}$ A ray is a half-line with vertex the origin and a cone is a set described by a set of rays. A function is conical if its graph is a cone, or what is the same (just more syllables), linearly homogeneous, being such that $\phi(x \lambda)=\phi(x) \lambda$. With demand governed by conical utility, the expansion paths, or loci of demand when expenditure varies while prices remain fixed, are rays.

${ }^{7}$ Samuelson and Swamy (1974) p. 570 attribute theorem and proof to Afriat (1972).
} 
That shows the sufficiency. Since, for all $p$,

$$
\theta(p) \phi(x) \leq p x
$$

for all $x$ with equality for some $x$, as assured with continuous $\phi$, it follows that

$$
\theta(p)=\min _{x} p x(\phi(x))^{-1}
$$

showing $\theta$ to be concave conical semi-increasing. Also for $x$ demandable at some prices, as would be the case for any $x$ if $\phi$ is concave, the inequality holds for all $p$ with equality for some $p$, showing

$$
\phi(x)=\min _{p}(\theta(p))^{-1} p x
$$

which, in case every $x$ is demandable at some prices, requires $\phi$ to be concave conical semi-increasing. But even when not all $x$ are demandable, because they lie in caves and are without a supporting hyperplane, here is a conical function defined for all $x$ that is effectively the same as the actual $\phi$ as far as any observable demand behaviour is concerned. So it appears that for the cost function factorization the utility function being conical is also necessary, beside being sufficient, as already remarked. Hence, with some details taken for granted, the Theorem is proved.

The question now is: what utility? A price index being wanted, by the theorem it must be conical, and with given demand data

$$
\left(p_{t}, x_{t}\right) \in B \times C(t=0,1, \ldots),
$$

and belief in efficiency, any utility to be entertained would, to fit the data, have to be such that

$$
P_{t} X_{t}=p_{t} x_{t}(t=0,1, \ldots)
$$

In any case

$$
P_{s} X_{t} \leq p_{s} X_{t}
$$

and so now, with

$$
L_{s t}=p_{s} x_{t} / p_{t} x_{t}
$$

the Laspeyres index, this condition requires the solubility of the system of inequalities

$$
\text { (L) } \quad L_{s t} \geq P_{s} / P_{t} \text {, }
$$

for price levels $P_{t}(t=0,1)$. A question is whether a solution exists. If one does, a conical utility can immediately be constructed that fits the given demand data and provides price levels, and consequently also quantity levels $X_{t}$, as required, where the $X_{t}$ are determined from

$$
P_{t} X_{t}=p_{t} X_{t}
$$

Thus, following the account for instance in Afriat (2004, p.12), introduce

$$
\widehat{\phi}_{i}(x)=P_{i}^{-1} p_{i} x
$$

and 


$$
\widehat{\phi}(x)=\min _{i} \widehat{\phi}_{i}(x)
$$

so this is a concave conical polyhedral utility function that, as seen in the same account, fits the demand data, with associated price indices as required, to make those prices indices true.

Another such function, concave conical, which fits the demand data, again with required values and the same associated price indices, is the polytope type function given by

$$
\breve{\phi}(x)=\max \left\{\sum_{i} X_{i} t_{i}: \sum_{i} x_{i} t_{i} \leq x, t_{i}>0\right\}^{8}
$$

and if $\phi$ is any other concave conical utility that fits the demands and takes the values $X_{i}$ at the points $X_{i}$ then

for all $x$.

$$
\breve{\phi}(x) \leq \phi(x) \leq \widehat{\phi}(x)
$$

Included in the above is a simple conical precursor of so-called "Afriat's theorem" on utility construction, put in service specifically for price index theory

\section{The True Index}

Every conical utility has associated with it a price index, derived from the utility-cost factorization applicable to such a function. A price index is termed true if it is connected with a conical utility that fits the demand data.

Every solution for price levels determines true price indices given by their ratios, the existence of a solution requiring the cyclical Laspeyres product test, that requires the cyclical Laspeyres products to be all at least 1 . It should be seen what all this has to say in reduction to the classical case of just two periods.

The existence of a solution for price levels implies the LP-inequality, and then any point in the LP-interval is expressible as a price index, obtained as the ratio of the price levels, which is true being associated with a conical utility that fits the data. Hence, as values for the price index, all points in the LP-interval are true-all equally, no one more true than another.

When this was mentioned a few decades ago, possibly at the Helsinki Meeting of the Econometric Society, August 1976, it was received with complete disbelief. ${ }^{9}$

Here is a formula to add to Fisher's collection, a bit different from the others:

PRICE-INDEX FORMULA: Any point in the LP-interval, if any.

\footnotetext{
${ }^{8}$ The function of this form introduced by Afriat (1971) is the constant-returns 'frontier production function' that gives a function representation, and at the same time a computational algorithm, for the production efficiency measurement method of Farrell (1957) (Afriat's colleague at DAE Cambridge whose work, done after he left, he at first missed) that marks the beginning of 'data envelope analysis' (DEA). The Afriat comment attached to Finn R.Førsund, and Nikias Sarafoglou (2005) gives a report.

While Afriat is usually given credit for first introduction of the 'non-parametric' approach, here now is opportunity to transfer credit to Farrell who made such an introduction for this case as it were implicitly if not explicitly in the way here exhibited.

The same type of function without constant-returns, worth knowing about, is used for the utility construction in Afriat (1961) but arbitrarily, or for simplicity, left aside in the account of (1964) where instead a polyhedral type function is used, as again in accounts such as Varian (1992, p. 133) of socalled “Afriat's Theorem”. It also served for the 1971 extension of Farrell's method.
}

\footnotetext{
${ }^{9}$ Proof is in Afriat (1977) 129-30.
} 
This paper draws attention to the generalization of this Formula for any number of periods, the (1981) New Formula, where price and quantity levels for the periods are all computed simultaneously, associated with a conical utility that fits the demand data for all the periods. The computations are by solution of a system of inequalities, so with a tolerance like in the above Formula, subject to a consistency condition that is a strengthening of ordinary revealed preference consistency. In the absence of consistency, an approach is made by an approximation method. This amounts to a complete, and elegant and practical, treatment of The Index Number Problem to which Afriat's attention was brought by Alan Brown the day he arrived at the Department of Applied Economics (DAE), Cambridge, in 1953, and concludes the assignment.

In the paper of 1982 on "The True Index", where there are elaborations about algorithms for consistency test and price-level computations, there is mention about normalizing price levels so they sum to 1 and are therefore represented by a point in the simplex of reference. Then the set of all price-level solutions, based on given data, is represented by a region in this simplex. In the case of three periods, when the reference simplex is simply a triangle, this opens the way to illuminating graphics, as presented in the paper. In the case of two periods the simplex of reference is a line segment and price-level solutions describe a subsegment corresponding to the PLinterval range of the price-index given by ratios of price-levels.

Irving Fisher favoured one particular formula out of the many (one or two hundred) he considered. This is his "ideal index" given by the geometric mean of the Laspeyres and Paasche indices. This favouritism is understandable because the formula is impressive and just about alone in meeting the Time Reversal requirement, one of his "tests" basic to the very idea of a price index. And moreover it is comfortably well into the interior of the interval bounded by the limiting Laspeyres and Paasche indices.

S. S. Byushgens (1925) submitted that if it could be taken that demand was governed by a homogeneous quadratic utility then the value of the associated price index would be given by Fisher's "ideal” formula. This result, which seemed at first, with initial optimism, to make the Fisher index "true", must have seemed spectacular. Possibly it is here that the idea of a true index made its first entry.

Of course now we have the Fisher index as true simply from belonging to the $L P$ interval, with countless fitting utilities, along with all the other points and no more true than any of them. However, with Byushgens, the Fisher index could be distinguished from the other points as being, not more true than the others - anyway impossible-but simply quadratically true-maybe. And maybe not! For if no quadratic utility can fit the data, Byushgens' Theorem, while still undoubtedly true, and still pretty, would be vacuous. This is a danger about which quite likely there had not been awareness at first.

In Afriat (1972), (1977), (1982) and (2004) ${ }^{10}$ there are accounts of issues to do with Fisher and Byushgens. These include an attempt to save Byushgens from the vacuity hazard by a weakening of his proposal, replacing quadratic by locally quadratic, rendering it with less interest except that it has been taken up by Diewert for doctrine about a formula to which-echoing Fisher with his terminology-he gives the name superlative, that in ordinary language must promise at least something good, while what that good should be is not known. Though our proposal for outright abandonment of all price index formulae would include Diewert's offer, it can still

\footnotetext{
${ }^{10}$ The 2004 volume contains earlier accounts beside an additional one.
} 
have attention for notable features while celebrated as the Swan Song of the PriceIndex Formula era.

A notable feature is citation style where a theorem is connected with a string of individuals that includes the originator with others not deserving or wanting credit. This lumping together of originator with readers in a quixotic generous distribution of credit can be joined at the same time with a scatter of compensatory withholdings.

But after all, we have been told:

If we should ever encounter a case where a theory is named for the correct man, it will be noted.

George J. Stigler

The Theory of Price (3rd edition), 1966, p.77

Stigler may have marked, if not just ignorance, a prevalence of ritual citations by separate individuals that amount to nothing more than greetings to friends. Such a phenomenon is consistent with "The Tale of Two Research Communities" and the tendency observed there to "stick to 'own camp' references", discovered by those early pioneers Finn R. Førsund and Nikias Sarafoglou (2005) in the field of Citation Analysis, a new field for which the way has been opened by advent of the computer, whose emergence Stigler might have been happy about.

We have been sidetracked, delivering the message to abandon useless formulae and enter a new path, to temper the abruptness and bring in the flavour of history.

\section{Bibliography}

Afriat, S. N. (1954) The Calculation of Index Numbers of the Standard and Cost of Living. Research Report, Department of Applied Economics, Cambridge.

- (1956) Theory of Economic Index Numbers. Research Report, Department of Applied Economics, Cambridge.

- (1960) The Conceptual Problem of a Cost of Living Index. Stanford Meeting of the Econometric Society, August 1960. Abstract in Econometrica 29, 3 (1961), 440.

- (1961). The Cost of Living Index. Research Memoranda Nos. 24 (March 1961), 27 (April 1961) and 29 (August 1961). Econometric Research Program, Princeton University.

- (1964) The Construction of Utility Functions from Expenditure Data. Cowles Foundation Discussion Paper No. 144 (October 1964), Yale University. First World Congress of the Econometric Society, Rome, September 1965. International Economic Review 8, 1 (1967), 67-77.

- (1971) Efficiency Estimation of Production Functions. Presented at Summer Meeting of the Econometric Society, Boulder, Colorado, September 1971. International Economic Review 13, 3 (October 1972), 568-98.

- (1972) The Theory of International Comparisons of Real Income and Prices. In International Comparisons of Prices and Output, Proceedings of the Conference at York University, Toronto, 1970, edited by D. J. Daly. National Bureau of Economic Reasearch, Studies in Income and Wealth Volume 37, New York, 1972. (Ch. I, 13-84). 
- (1973) On a System of Inequalities in Demand Analysis: an Extension of the Classical Method. International Economic Review 14, 2 (June 1973), 460-72.

- (1977) The Price Index. Cambridge University Press, 1977. Pp. 203. 2nd impression, September 1978.

- (1978) Index Numbers in Theory and Practice by R. G. D. Allen. Canadian Journal of Economics 11, 2 (May), 367-369. Available at

(under Various, then Excavations).

$$
\text { http://www.econ-pol.unisi.it/ afriat }
$$

- (1981) On the Constructibility of Consistent Price Indices Between Several Periods Simultaneously. In Essays in Theory and Measurement of Demand: in honour of Sir Richard Stone, edited by Angus Deaton. Cambridge University Press. 133-161. Reproduced in Afriat (2004).

- (1982) The True Index. In Demand, Equilibrium and Trade: Essays in Honour of Ivor F. Pearce, Proceedings of the Conference at the University of Southampton, 5-7 January 1982, edited by A. Ingham and A.M. Ulph. London: Macmillan, 1984.37-56. Reproduced in Afriat (2004).

- (1987) The Cost of Living. Part III in Logic of Choice and Economic Theory. Oxford: Clarendon Press, 1987.

- (1988) The price index, the concept in theory and practice, and its extensions. Institute of Socio-Economic Planning, Tsukuba University, 26 April, 1988; also Economics Department, Osaka University, and Tohoku University, Sendei.

- (2004) The Price Index and its Extension-A chapter in economic measurement, Foreword by Angus Deaton. London and New York: Routledge. Routledge Frontiers of Political Economy, 65.

- and Nuri Jazairi (1988), Fisher's Test Approach to Index Numbers. Encyclopedia of Statistical Sciences, edited by S. Kotz and Norman L. Johnson. John Wiley \& Sons.

Allen, R. G. D. (1975) Index Numbers in Theory and Practice. Macmillan.

- (1978) The Price Index by S. N. Afriat.. J. Roy. Stat. Soc. Series A (General) 141, 3, 418.

Andreoni, James and John Miller (2002), Giving according to GARP: An experimental test of the consistency of preferences for altruism, Econometrica 70, 2, 737-753.

Barnett, William. A., Ki-Hong Choi and T. M. Sinclair (2003), The differential approach to superlative index number theory. Journal of Agricultural and Applied Economics (Henri Theil Memorial Issue) 35; 59-64.

Blundell, R., M. Browning, and I. Crawford (2003), Nonparametric Engel curves and revealed preference, Econometrica 71, 1, 205-240.

Blundell, Richard (2005), How revealing is revealed preference? European Economic Journal 3, 211-235.

Bowley, A.I. (1923), Review of The Making of Index Numbers by Irving Fisher. Economic Journal 33: 90-94. 
Byushgens, S. S. (1925), Ob odnom klasse giperpoverkhnostey: po povodu 'idealnovo indeksa' Irving Fischer' a pokupatelnoi sili deneg. Mathematischeskii Sbornik 32, 625-31. [S. S. Buscheguennce, Sur une classe des hypersurfaces: ápropos de 'l’index idéal' de M. Irving Fischer. Recueil Mathematique (Moscow) 32 (1925), 625-31.]

Caves, Douglas W., Laurits R. Christensen and Walter E. Diewert (1982b), Multilateral Comparison of Output, Input, and Productivity Using Superlative Index Numbers. Economic Journal 92 (365), 73-86 ( ref. p. 41)

Deaton, Angus (1979a), The Price Index by S. N. Afriat. Journal of the American Statistical Association 74, 365 (March), 251.

- (1979b), The Distance Function and Consumer Behaviour with Applications to Index Numbers and Optimal Taxation. Review of Economic Studies 46, 391-405.

- (ed.) (1981), Essays in Theory and Measurement of Demand: in honour of Sir Richard Stone. Cambridge University Press.

- (2004), Foreword to Afriat (2004).

- and J. Muellbauer (1980), Economics and Consumer Behaviour. Cambridge University Press.

Diewert, W. Erwin (1976), Exact and Superlative Index Numbers, Journal of Econometrics 4: 115-145.

- (1978), Superlative Index Numbers and Consistency in Aggregation, Econometrica 46: 883-900.

Dimand, Robert W. (1998), The quest for an ideal index: Irving Fisher and The Making of Index Numbers. In The Economic Mind in America: Essays in the History of American Economics edited by Malcolm Rutherford. London and New York: Routledge.

Dowrick, Steve and John Quiggin (1994), International Comparisons of Living Standards and Tastes: A Revealed-Preference Analysis, American Economic Review 84, 1, 332-341.

- (1997), True Measures of GDP and Convergence, American Economic Review 87 1 (March), 41-64.

Edgeworth, F. Y. (1925), The Plurality of Index Numbers, Economic Journal 35: 379388.

Eichhorn, Wolfgang (1976), Fisher's Tests Revisited. Econometrica 44, 2 (March), 247-56.

Famulari, M. (1995), A household-based, nonparametric test of demand theory. Review of Economics and Statistics 77, 372-383.

Farrell, M. J. (1957), The measurement of productive efficiency. J. Roy. Stat. Soc., A, 120 (3), 253-81.

Fisher, Irving (1922), The Making of Index Numbers, Boston: Houghton-Mifflin.

Førsund, Finn R. and Nikias Sarafoglou (2005), The Tale of Two Research Communities: The Diffusion of Research on Productive Efficiency. Presented at IFORS conference, Athens, 1999, revision in International Journal of Product- 
ion Economics, and in University of Siena Quaderno N. 446 (February 2005) with a Comment by Sydney Afriat. Available at http://www.econ-pol.unisi.it/quaderni.html;

Comment also available at http://www.econ-pol.unisi.it/ afriat (under Various, $3^{\text {rd }}$ item).

Gross, John (1995), Testing data for consistency with revealed preference, Review of Economics and Statistics 77, 4, 701-710.

Hicks, J. R. (1942), Consumers' surplus and index-numbers. Rev. Econ. Studies 9, 2, 126-37.

- (1948), Value and Capital, $2^{\text {nd }}$ ed. Oxford: Clarendon Press.

- (1956), A Revision of Demand Theory. Oxford: Clarendon Press.

Hill, Robert J. (2004) Superlative index numbers: not all of them are super. Journal of Economatrics 130, 25-43.

Jorgenson, Dale W. and Zvi Griliches (1967), The Explanation of Productivity Change, Review of Economic Studies 34, 3, 249-83.

Jorgenson, Dale W. and Zvi Griliches (1971), Divisia Index Numbers and Productivity Measurement, Review of Income and Wealth 17, 2, 227-9.

Konüs, A.A. and S.S. Byushgens (1926), K probleme pokupatelnoi cili deneg (On the Problem of the Purchasing Power of Money), Voprosi Konyunkturi II(1) (supplement to Economic Bulletin of the Conjuncture Institute), 151-172.

Lau L. J. (1979), On exact index numbers. Review of Economics and Statistics 61; 73-82.

Malmquist, S. (1953), Index numbers and indifference surfaces. Trabajos de Estatistics 4, 209-42.

Manser, Marilyn E. and Richard J. McDonald (1988), An analysis of substitution bias in measuring inflation, 1959-85. Econometrica 56, 4 (July), 909-930.

Milana, Carlo (1993), Numeri indici. Enciclopedia Italiana, Institute of the Italian Encyclopedia founded by Giovanni Treccani, Rome, 5th Appendix (1979-1992), 704-9.

- (1996), Le distorsioni dell'indice aggregato dei prezzi al consumo. Rivista di Politica Economica 86, 5, 57-111.

- (2000), Economic Analysis of Production Price Indexes by Franklin M. Fisher and Karl Shell. Economic Systems Research 12, 3, 433-36.

- (2001), The Input-Output Structural Decomposition Analysis of 'Flexible' Production Systems. In M. L. Lahr and E. Dientzenbacher (eds.), Input-Output Analysis: Frontiers and Extensions, New York, Palgrave, 349-80.

- (2005), Exact and Superlative Index Numbers Revisited, EUKLEMS Working Paper No. 3 (http://www.euklems.net).

- (2006a), Productivity Measurement in a Changing Structure of Production: The Case of Italy. EU KLEMS project.

- (2006b), A Net Profit Approach to Productivity Measurement, with an application to Italy. OECD Workshop, Berne, October. 
- (2006c), Measurement Problems with Non-Invariant Economic Index Numbers of Outputs, Inputs, and Productivity: The Case of Italy, EUKLEMS Working Paper No. 11 (http://www.euklems.net).

Samuelson, P.A. and S. Swamy (1974) Invariant Economic Index Numbers and Canonical Duality: Survey and Synthesis, American Economic Review 64, 4 (September), 566-93

Stigler, George J. (1966) The Theory of Price (3rd ed.). New York: Macmillan.

Stone, Richard (1951), The Role of Measurement in Economics. Cambridge University Press.

- (1954), Linear Expenditure Systems and Demand Analysis; an Application to the Patternof British Demand. Economic Journal 64 (1954). 511-24.

- (1956), Quantity and Price Indexes in National Accounts. OEEC, Paris.

- assisted by D.A. Rowe, W.J. Corlett, R. Hurstfield, and M. Potter (1966), The Measurement of Consumer's Expenditure and Behaviour in the United Kingdom,1920-1938, Vol. 1. Cambridge University Press.

Varian, Hal R. (1992), Microeconomic Analysis, $3^{\text {rd }}$ ed. W. W. Norton \& Co.

\section{Appendix \\ Fisher's “Superlative” Index Numbers}

Irving Fisher (1922, 244-48) ranked 134 index number formulas according to their numerical distance from the "ideal" geometric mean of the Laspeyres and Paasche indices and separated them "arbitrarily into several classes in increasing order of merit. The first twelve index numbers, constituting the first of these classes, are labeled, rather harshly perhaps, as 'worthless' index numbers to designate the fact that they are the worst. The other six classes are labeled as poor, fair, good, very good, excellent, and superlative” (p. 244).

He then, classified ten index number formulas in the superlative group because, in his numerical example, they performed very closely to the "ideal" geometric mean of the Laspeyres and Paasche indexes. He claimed that all these formulas correspond to combinations of the Laspeyres and Paasche including the direct and implicit Walsh index numbers, one combination of these last two formulas, and a couple of combinations of direct and implicit Törnqvist-type index numbers. Fisher lists 10 formulas in the class of "superlative" index numbers in addition to his "ideal" formula for the price index.

Let $p_{i}^{t}$ and $q_{i}^{t}$ represent, respectively, the price and quantity of the $i^{\text {th }}$ commodity during the observed period $t$ and $V \equiv \frac{\sum_{i} p_{i}^{1} q_{i}^{1}}{\sum_{i} p_{i}^{0} q_{i}^{0}}$. Fisher's “superlative” index numbers are presented here in the original inverse order of remoteness from the ideal (353) (the formulas are identified with Fisher's code and the page of The Making of Index Numbers where they are defined is indicated in parenthesis ${ }^{11}$ ):

11 See Fisher (1922, Appendix V) for the full list of the 134 formulas. 
(11) $5323 \equiv \sqrt{323 \times 325}$ (geometric mean of two Törnqvist-based index numbers) p. 486),

(10) $1323 \equiv \sqrt{1123 \times 1124}$ (p. 484),

(9) $1153 \equiv \frac{\sum_{i}\left(q_{i}^{0} q_{i}^{1}\right)^{1 / 2} p_{i}^{1}}{\sum_{i}\left(q_{i}^{0} q_{i}^{1}\right)^{1 / 2} p_{i}^{0}}$ (Walsh index number) (p. 483),

(8) $1353 \equiv \sqrt{1153 \times 1154}$ (p. 484),

(7) $1154 \equiv V / \frac{\sum_{i}\left(p_{i}^{0} p_{i}^{1}\right)^{1 / 2} q_{i}^{1}}{\sum_{i}\left(p_{i}^{0} p_{i}^{1}\right)^{1 / 2} q_{i}^{0}}$ (implicit Walsh index number) (p. 483),

(6) $2154 \equiv V /\left(\sum_{i} \frac{p_{i}^{0}+p_{i}^{1}}{2} q_{i}^{1} / \sum_{i} \frac{p_{i}^{0}+p_{i}^{1}}{2} q_{i}^{0}\right)=\frac{1+\frac{\sum_{i} p_{i}^{1} q_{i}^{0}}{\sum_{i} p_{i}^{0} q_{i}^{0}}}{1+\frac{\sum_{i} p_{i}^{0} q_{i}^{1}}{\sum_{i} p_{i}^{1} q_{i}^{1}}}$ (p. 484 and 488),

(5) $2353 \equiv \sqrt{2153 \times 2154}$ (p. 484),

(4) $2153 \equiv \sum_{i} \frac{q_{i}^{0}+q_{i}^{1}}{2} p_{i}^{1} / \sum_{i} \frac{q_{i}^{0}+q_{i}^{1}}{2} p_{i}^{0}=\frac{\sum_{i}\left(q_{i}^{0}+q_{i}^{1}\right) p_{i}^{1}}{\sum_{i}\left(q_{i}^{0}+q_{i}^{1}\right) p_{i}^{0}} \quad$ (p. 484 and p. 488),

(3) $8054 \equiv 2 /\left[\frac{\sum_{i} p_{i}^{0} q_{i}^{0}}{\sum_{i} p_{i}^{1} q_{i}^{0}}+\frac{\sum_{i} p_{i}^{0} q_{i}^{1}}{\sum_{i} p_{i}^{1} q_{i}^{1}}\right]$ (p. 487),

(2) $8053 \equiv \frac{53+54}{2}=\left[\frac{\sum_{i} p_{i}^{1} q_{i}^{0}}{\sum_{i} p_{i}^{0} q_{i}^{0}}+\frac{\sum_{i} p_{i}^{1} q_{i}^{1}}{\sum_{i} p_{i}^{0} q_{i}^{1}}\right] / 2$ (487),

(1) $353 \equiv \sqrt{53 \times 54}=\sqrt{\frac{\sum_{i} p_{i}^{1} q_{i}^{0}}{\sum_{i} p_{i}^{0} q_{i}^{0}} \cdot \frac{\sum_{i} p_{i}^{1} q_{i}^{1}}{\sum_{i} p_{i}^{0} q_{i}^{1}}}$ (Fisher “ideal” index number) (p. 482), with

$1123 \equiv \prod\left(\frac{p_{i}^{1}}{p_{i}^{0}}\right)^{\sqrt{p_{i}^{0} q_{i}^{0} p_{i}^{1} q_{i}^{1}} / \sum_{j} \sqrt{p_{j}^{0} q_{j}^{0} p_{j}^{1} q_{j}^{1}}}$ (p. 483),

$1124 \equiv V / \prod\left(\frac{q_{i}^{1}}{q_{i}^{0}}\right)^{\sqrt{p_{i}^{0} q_{i}^{0} p_{i}^{1} q_{i}^{1}} / \sum_{j} \sqrt{p_{j}^{0} q_{j}^{0} p_{j}^{1} q_{j}^{1}}}$ (p. 483),

$323 \equiv \sqrt[4]{23 \times 24 \times 29 \times 30}=\sqrt{123 \times 124}=\sqrt{223 \times 229}$ (p. 480), 


$$
\begin{aligned}
& 325 \equiv \sqrt[4]{25 \times 26 \times 27 \times 28}=\sqrt{125 \times 126}=\sqrt{225 \times 227} \text { (p. 480), }
\end{aligned}
$$

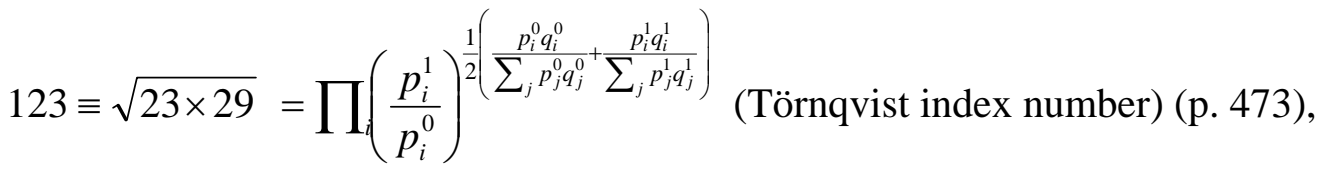

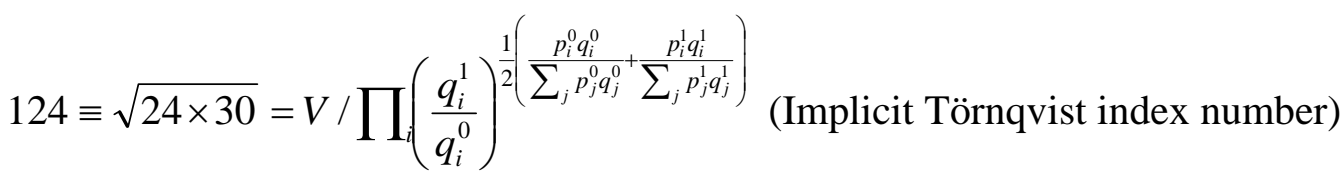

$$
\begin{aligned}
& \text { (p. 473), }
\end{aligned}
$$

$125 \equiv \sqrt{25 \times 27}$ (p. 473)，

$126 \equiv \sqrt{26 \times 28} \quad$ (р. 473),

$223 \equiv \sqrt{23 \times 24}($ p. 477),

$225 \equiv \sqrt{25 \times 26} \quad($ p. 477),

$227 \equiv \sqrt{27 \times 28} \quad$ (р. 477)

$229 \equiv \sqrt{29 \times 30} \quad$ (р. 477)，

$23 \equiv \prod\left(\frac{p_{i}^{1}}{p_{i}^{0}}\right)^{p_{i}^{0} q_{i}^{0} / \sum_{j} p_{j}^{0} q_{j}^{0}} \quad$ (p. 468),

$24 \equiv V / \prod\left(\frac{q_{i}^{1}}{q_{i}^{0}}\right)^{p_{i}^{0} q_{i}^{0} / \sum_{j} p_{j}^{0} q_{j}^{0}} \quad$ (p. 468),

$25 \equiv \prod\left(\frac{p_{i}^{1}}{p_{i}^{0}}\right)^{p_{i}^{0} q_{i}^{1} / \sum_{j} p_{j}^{0} q_{j}^{1}} \quad$ (p. 468),

$26 \equiv V / \prod\left(\frac{q_{i}^{1}}{q_{i}^{0}}\right)^{p_{i}^{1} q_{i}^{0} / \sum_{j} p_{j}^{1} q_{j}^{0}} \quad$ (p. 468),

$27 \equiv \prod\left(\frac{p_{i}^{1}}{p_{i}^{0}}\right)^{p_{i}^{1} q_{i}^{0} / \sum_{j} p_{j}^{1} q_{j}^{0}} \quad$ (p. 468),

$28 \equiv V / \prod\left(\frac{q_{i}^{1}}{q_{i}^{0}}\right)^{p_{0}^{0} q_{i}^{1} / \sum_{j} p_{j}^{0} q_{j}^{1}} \quad$ (p. 468), 
$29 \equiv \prod_{i}\left(\frac{p_{i}^{1}}{p_{i}^{0}}\right)^{p_{i}^{1} q_{i}^{1} / \sum_{j} p_{j}^{1} q_{j}^{1}} \quad$ (p. 468),

$30 \equiv V / \prod\left(\frac{q_{i}^{1}}{q_{i}^{0}}\right)^{p_{i}^{1} q_{i}^{1} / \sum_{j} p_{j}^{1} q_{j}^{1}} \quad$ (p. 468),

$53 \equiv \frac{\sum_{i} p_{i}^{1} q_{i}^{0}}{\sum_{i} p_{i}^{0} q_{i}^{0}} \quad$ (Laspeyres index number) $\left(\right.$ p. 471) $=V / \frac{\sum_{i} p_{i}^{1} q_{i}^{1}}{\sum_{i} p_{i}^{1} q_{i}^{0}}$

$54 \equiv \frac{\sum_{i} p_{i}^{1} q_{i}^{1}}{\sum_{i} p_{i}^{0} q_{i}^{1}}$ (Paasche index number) (p. 471) $=V / \frac{\sum_{i} p_{i}^{0} q_{i}^{1}}{\sum_{i} p_{i}^{0} q_{i}^{0}}$

Moreover, formulas numbered 103, 104, 105, 106, 153, 154, 203, 205, 217, 219, 253, 259, 303, 305 reduce to 353.

In the numerical example performed by Fisher, the closest formula to 353 is 8053, which is the arithmetic average of 53 (Laspeyres) and 54 (Paasche) index numbers. Fisher claimed that most of "superlative" index numbers are various combinations of 53 and 54.

These index numbers should be contrasted with the quadratic mean-of-order- $r$ index numbers by Diewert (1976, 130-1) and called "superlative” by him using Fisher's (1922, p. 247) terminology (but in a different sense). These are encompassed by the following general formula:

$P_{D} \equiv\left[\frac{\sum_{i} s_{i}^{0}\left(p_{i}^{1} / p_{i}^{0}\right)^{r / 2}}{\sum_{i} s_{i}^{1}\left(p_{i}^{0} / p_{i}^{1}\right)^{r / 2}}\right]^{\frac{1}{r}}$

where $s_{i}^{t} \equiv \frac{p_{i}^{t} q_{i}^{t}}{\sum_{j} p_{j}^{t} q_{j}^{t}}$ for $t=0,1$ and with $P_{D}$ reducing to the Fisher "ideal" index with $r=2$, to the implicit Walsh index (Fisher's formula 1154) with $r=1$, and to the Törnqvist index number (Fisher's formula 123) at the limit as $r \rightarrow 0$. It can be shown (Diewert, 1976) that, if the shares $s_{i}^{t}$ are those derivable exactly from the true utilitycost function, then this may have the following quadratic mean-of-order-r functional form:

$c^{t}(p)=\left[\sum_{i} \alpha_{i j}^{t}\left(p_{i} p_{j}\right)^{r / 2}\right]^{1 / r}$ with $r \neq 0$, which tends to the translog functional form $\ln c^{t}(p)=a_{0}^{t}+\sum_{i} a_{i}^{t} \ln p_{i}+\sum_{i} \sum_{j} a_{i j}^{t} \ln p_{i} \ln p_{j} \quad$ as $r \rightarrow 0$.

Following Milana (2005) and generalizing Caves et al. (1982), it can be shown that the equality $P_{D}=\left[\frac{c^{0}\left(p^{1}\right)}{c^{0}\left(p^{0}\right)}\right]^{\lambda}\left[\frac{c^{1}\left(p^{1}\right)}{c^{1}\left(p^{0}\right)}\right]^{1-\lambda} \quad$ is obtained with some real value of $\lambda$.

Caves et. al. (1982) have considered the case of a translog functional form where the parameters of the second-order terms are constant, that is $a_{i j}^{t}=\bar{a}_{i j}$. In this case, $\lambda=1 / 2$. number

Alternatively, it is possible to define a quadratic mean-of-order- $r$ quantity index 
$Q_{D} \equiv\left[\frac{\sum_{i} s_{i}^{0}\left(q_{i}^{1} / q_{i}^{0}\right)^{r / 2}}{\sum_{i} s_{i}^{1}\left(q_{i}^{0} / q_{i}^{1}\right)^{r / 2}}\right]^{\frac{1}{r}}$, which reduces to the Fisher "ideal" quantity index with $r=$

2, to the implicit Walsh quantity index with $r=1$, and to the Törnqvist quantity index number at the limit as $r \rightarrow 0$. If the shares $s_{i}^{t}$ are those derivable exactly from the true utility function, then this index number is exact for a utility-based distance function $\delta^{t}(q)$ (Deaton, 1979) in the sense that it is a weighted (geometric) average of two Malmquist (1953) index numbers defined as distance function ratios, that is $Q_{D}=\left[\frac{\delta^{0}\left(q^{1}\right)}{\delta^{0}\left(q^{0}\right)}\right]^{\lambda}\left[\frac{\delta^{1}\left(q^{1}\right)}{\delta^{1}\left(q^{0}\right)}\right]^{1-\lambda}$ for some real value of $\lambda$,

where $\delta^{t}(q)=\left[\sum_{i} \beta_{i j}^{t}\left(q_{i} q_{j}\right)^{r / 2}\right]^{1 / r}$ with $r \neq 0$, which tends to the translog functional form

$\ln \delta^{t}(q)=a_{0}^{t}+\sum_{i} a_{i}^{t} \ln q_{i}+\sum_{i} \sum_{j} a_{i j}^{t} \ln q_{i} \ln q_{j} \quad$ as $r \rightarrow 0$.

In particular, $\lambda=1 / 2$ when $\delta^{0}$ and $\delta^{1}$ are quadratic functions with the same parameters in the second-order terms.

It is tempting to derive the implicit quadratic mean-of-order- $r$ price index as the ratio $\widetilde{P}_{D} \equiv V / Q_{D}$, but the homotheticity of the underlying economic function is a necessity as well as a sufficiency for the existence (and invariance) of such an index, as pointed out by Samuelson and Swamy (1974, p. 570) echoing Afriat's (1972) factorization theorem. If this is not the case, the obtained implicit price index is spurious and may not even respect the required homogeneity properties.

It is immediate to see that, except the implicit Walsh index number and Fisher's “ideal” itself, Diewert's "superlative" index numbers are not "superlative” in Fisher's (1922, 244-48) sense ${ }^{12}$. The implicit Walsh index number, which is given by formula 1154 in Fisher's list, corresponds to Diewert's quadratic mean of order-1 index number, whereas Fisher's “ideal” index number corresponds to Diewert's quadratic

\footnotetext{
${ }^{12}$ The Törnqvist index, for example, (corresponding to formula 123 in Fisher, 1922, p. 473) is seen as the most superlative by Caves, Christensen, and Diewert (1982, p. 41) and Diewert (2004, p. 450) whereas it was not deemed "superlative" by Fisher (1922, p. 247), who classified it, in a descending order of merit, below the classes of "excellent" and "superlative" index numbers, with the last group ranked at the top position.

Note from CM to SA: This is not the only critical remark that we may make. The Törnqvist index number is exact for a particular quadratic function (the translog) just as the Fisher "ideal" is exact for a simple quadratic function. It does not matter that the Törnqvist index is exact for a translog function that (as shown by Caves et al., 1982) is not necessarily homogeneous (Milana, 2005 has shown that also the other index numbers that are "superlative" in Diewert's sense are exact for specific quadratic functions that are not necessarily homogeneous). The main point is that it is not true that: (1) these index numbers are second-order approximations to the "true" index and to each other, (2) this "true" index does not exist at all in the non-homothetic (or non-homogeneous) case (see your LP-inequality theorem) and, therefore, the Caves et al. theorem is vacuous implying that the obtained index number is, in more familiar terms, "path dependent". Under these circumstances, the Caves, et al. results fall under the criticism raised by your earlier contributions and our present paper.

Note from SA to CM: Very interesting for experts like yourself and some others. But this paper, as you are aware, proposes the abandonment of all price-index formulae and whatever anyone may have had to say about any of them, and offers an entirely different approach to "The Index Number Problem".
} 
mean of order-2 index number. For the reasons given in Milana (2005), however, all Diewert's and Fisher's indexes cannot be defined as approximating the unknown true index number (if this exists) up to the second order and cannot be considered to be "superlative" also in Diewert's sense of (1976), (1978). 